\title{
The Relationship Between the Mental Health of School Teachers and the School Organizational Climate During the COVID-19
}

\author{
Moinka Dau ${ }^{1}$, Dr. Ramendeap Araor ${ }^{2}$ \\ ${ }^{1}$ Principal, B. C. M. College of Education, Ludhiana \\ ${ }^{2}$ Assistant Professor, B. C. M. College of Education, Ludhiana
}

\begin{abstract}
The COVID-19 pandemic has led teachers to an unpredictable scenario where the lockdown situation has accelerated the shift from traditional to online educational methods and relationships have been altered in direct contact with the others, with implications of changes in Mental Health. This global health crisis has affected the Mental and Psychological Health of the people around the world. However, a little is known about the impact of COVID-19 among school teachers. Therefore, a study was conducted to determine the impact of the COVID-19 pandemic on Mental Health of School teachers. Self-made test was used to collect the data from school teachers using google form. t-test was used to find the differences in Mental Health of School teachers in relation to their Gender and locale and Type of School. Results revealed that significant differences exist between Male and Female school teachers. Female teachers have better Mental Health than their Male counterparts. School Teachers working in Rural area have higher scores as compared to teaches posted at schools located in urban areas. Teachers working in Government Schools have better Mental Health. This study contributes to the growing literature on the impact of the pandemic COVID-19.
\end{abstract}

\section{Introduction}

As it is the teacher who is the kingpin of the entire educational system, all the developmental activities related to social, cultural, intellectual, aesthetic and emotional aspects of child's personality revolve around him. It is essential to see that the teachers are satisfied with their life and job. So that they can produce best citizens who can become the backbone of the society. But if the conditions under which he works are strained, it not only tends to incapacitate him but also affect the performance of his multifarious functions.

The COVID-19 pandemic has changed our understanding of the world as we previously knew it. The strong measures of social distancing and lockdown that have been applied since the beginning of the pandemic have led to significant changes in social relationships, which, for many people, have created feelings of isolation and loneliness (Smith and Lim, 2020). Indeed, the rapid transmission of COVID-19 throughout the world has health, social, psychological, economic and, of course, educational consequences. In fact, school closure has been, on a global scale, one of the most widely used measures for helping to maintain social distancing and to decrease infections (Sheikh et al., 2020; Van Lancker and Parolin, 2020; Viner et al., 2020). Studies have found for teachers working from home using Information and Communication Technologies (ICT) show feelings of tension, anxiety, exhaustion, and decreased job satisfaction (Cuervo et al., 2018), and of course in times of a pandemic these were the only tools that were available to teachers.

Research carried out in several countries has revealed that in the teaching profession there have been many casualties of Stress, Anxiety, and Depression (Ryan et al., 2017; Vonder Embse et al., 2019). United Nations Educational, Scientific and Cultural Organization (2020a) had already identified confusion and stress among teachers as being one of the adverse consequences of school closures, due to the abruptness of such measures, uncertainty about their duration, and a lack of familiarity with distance education. Even, educational administrations have not stopped the scholar year, so that teachers have found themselves coping with online education at any level (Wang and Zhao, 2020) while attending to another personal issues. Thus, investigator attempts to study the Mental Health of school teachers in relation to Gender, Locale and Type of School.

\section{Mental Health}

Mental health denotes a person's emotional, psychological and social well-being, which affects one's thinking, feeling and action. Mental health is important at every stage of life from childhood and adolescence through adulthood to old age as it helps to cope with stress. The World Health Organization (2018) defined Mental Health as, "a state of well-being in which every individual recognizes his or her abilities, can cope with the normal stresses of life, can function productively and fruitfully and can contribute to his/her community". Mental Halth is also described as a "dynamic state of internal equilibrium which enables individuals to use their abilities in harmony with universal values of society". Galderisi et al., (2017) defined Mental Health as basic cognitive and social skills, modulate and express one's own emotions, as well as empathize with others; flexibility, ability to recognize, cope with adverse life events and function in social roles; the harmonious relationship between body and mind which contribute, to varying degrees, to the state of internal equilibrium. Hence, Mental Health can be described as a state of normal condition, where every individual can function efficiently towards himself or herself and in their respective community; in general, it is an absence of mental illness. Mental health is about improving the competencies of individuals and communities and enabling them to achieve their self-determined goals. Hence, Mental Health should be 
a concern for all of us, rather than only for those who suffer from a mental illness.

\section{Literature Review}

During COVID-19 pandemic, we are living in time of growing complexities and pressures where human constitution and capacities are taxes severely. The stress relating to occupation and health have become predominant feature of modern life exerting farreaching effects on employee's behaviour and satisfaction. Though a moderate degree of stress hasbeen noted, creating as well as promoting employee's inclination towards the occupation, but excessive and consistent occupational stress results in life dissatisfaction, depression and in some cases serious Mental and Physical problems.

Pandemic has had a significant impact on the Mental Health of teachers and students. In China, a study conducted by Huang and Zhao Galderisi et al., (2020) found that $35.1 \%$ of teachers and students presented moderate symptoms of anxiety and $21 \%$ moderate symptoms of depression, whereas in Germany, teachers experienced a medium-to-high amount of stress during lockdown which impact Mental Health as investigated by Klapproth, Federkeil, Heinschke and Jungmann (2020) In the United Kingdom (UK), teachers reported high levels of anxiety Allen, Jerrimand Sims (2020) and in Chile, the Pandemic negatively affected teachers' quality of life, especially among women and younger teachers Lizana, Vega-Fernadez, Gomez-Bruton, Leyton and Lera (2020). Pai and Vella (2021) investigated loneliness has been a significant issue during the current COVID-19 pandemic and loneliness is positively associated with mental health symptoms. Hasson and et al (2021) surveyed Physical activity is one of the most efficacious pathways to promoting mental and physical health, preventing disease, and, most important during the COVID-19 pandemic, bolstering a stronger immune system. Zhang and Kou (2021) investigated how implicit theories of health and consideration of future consequences influence people's engagement in health-protective behaviours during the COVID-19 pandemic in China.

Duraku, Zamira and Hoxha (2020) investigated impact of COVID-19 on education and on the well-being of teachers, parents and students. Results showed circumstances created by COVID-19 have caused a great deal of concern among students, parents and teachers about assessment, distance learning inadequacy, and student overload. Review of related literature revealed that Mental Health of teachers is affected during COVID-19.

Thus investigator study Mental Health of school teachers during COVID 19

\section{Objectives}

1) To study Mental Health of male and female school teachers during COVID-19.

2) To study Mental Health of teachers working in schools located in rural and urban area during COVID-19.

3) To study Mental Health of teachers working in Government and Private Schools during COVID-19.
Hypotheses

1) There is no significant difference between Mental Health of male and female school teachers during COVID-19.

2) There is no significant difference between Mental Health of teachers working in schools located in rural and urban areas during COVID-19.

3) There is no significant difference between Mental Health of teachers working in Government and Private Schools during COVID-19.

\section{Delimitations}

The study was delimited to the schools of Punjab only. Data of 544 school teachers have been taken for the study.

\section{Methodology}

1) The researcher used Descriptive Survey method to study Mental Health of School Teachers during Covid-19.

2) A self-made questionnaire was used to collect data through a google form links which was shared with School Teacher using social media like e-mail and what's app.

\section{Analysis and Discussion}

The results of statistical analysis for the present investigation have been presented with the help of tabulation, showing the descriptive statistical values for the said variables. Additionally, gender differences and differences between teachers working at Urban/ rural and Govt. /Private schools was calculated

Table 1: Comparison of Mean Scores of Mental Health of Male and Female School Teachers

\begin{tabular}{|c|r|r|r|r|r|}
\hline Gender & N & Mean & S. D. & t-value & Level of Significance \\
\cline { 1 - 3 } Male & 137 & 26.56 & 7.93 & \multirow{2}{*}{1.14} & Not significant \\
\hline Female & 407 & 27.44 & 7.94 & & \\
\hline
\end{tabular}

On analyzing the data given in Table 1 it is observed that the mean score of male school teachers is 26.54 and S. D. is 7.93 and the mean scores of female school teachers is 27.44 and S. D. is 7.94. The calculated t-value is 1.14 which is not significant at.05 level. Hence the null hypothesis "There is no significant difference between Mental Health of Male and female school teachers" is accepted.

Thus the result showed that on the basis of Gender school teachers have no significant difference in Mental Health. However female school teachers have better Mental Health than male school teachers.

Table 2: Comparison of Mean Scores of Mental Health of school teachers working in Rural and Urban schools

\begin{tabular}{|c|c|c|c|c|c|}
\hline Locale of School & N & Mean & SD & t-value & Level of Significance \\
\cline { 1 - 4 } Rural & 291 & 27.49 & 7.94 & \multirow{2}{*}{0.77} & \multirow{2}{*}{ Not significant } \\
\hline Urban & 253 & 26.90 & 8.13 & & \\
\hline
\end{tabular}

On analyzing the data given in Table 2 it is observed that the mean score of school teachers working in rural schools is 27.49 and S. D. is 7.94 and the mean scores of school teachers working in urban area is 26.90 and S. D. is 8.13. The calculated t-value is 0.77 which is not significant at.05 
level. Hence the second null hypothesis "There is no significant difference between Mental Health of teachers working Schools located in rural and urban areas" is accepted.

Thus the result showed that on the basis of location of school teachers have no significant difference in Mental Health. However teachers of rural schools have better Mental Health than urban school teachers.

Table 3: Comparison of Mean Scores of Mental Health of School Teachers working in Government and Private schools

\begin{tabular}{|c|c|c|c|c|c|}
\hline Type of School & $\mathrm{N}$ & Mean & SD & $\mathrm{t}$-value & Level of Significance \\
\hline Government & 254 & 26.19 & 7.94 & \multirow{2}{*}{5.81} & .01 \\
\hline Private & 290 & 22.3 & 7.92 & & \\
\hline
\end{tabular}

1) On analyzing the data given in Table 3 it is observed that the mean score of government school teachers is 26.19 and S. D. is 7.94 and the mean scores of private school teachers is 22.3 and S. D. is 7.92. The calculated $\mathrm{t}$-value is 5.81 which is significant at.01 level. Hence the second null hypothesis "There is no significant difference between Mental Health of teachers working in Government and Private Schools." is rejected.

2) Thus the result shows that on the basis of type of school teachers have significant difference in Mental Health.

\section{Conclusions}

On the basis of the study, following results have been drawn

- There was no significant difference in mental health of male and female school teachers. Females have better mental health than male school teachers.

- There was no significant difference in mental health of school teachers working in rural and urban area. School teachers working in rural area have better Mental Health than school teachers working in urban area.

- There was significant difference in mental health of school teachers working in government and private schools. Mental health of school teachers working in government schools is much better than teachers working in private schools

\section{Suggestions}

- School teachers should be facilitated with Techno savvy environment. School can provide them free wi-fi facility and gadgets to them.

- Teachers should be encouraged to participate in seminars, workshops and conferences to enhance their technical skills.

- Peer group learning should be promoted to remove hitch of learning of teachers.

- Special counsellor can be appointed to improve Mental Health of Teaches.

- Small celebrations can be organized in schools for cordial relation between staff members.

- Ice breaking sessions and stress bursting activities can be organized in the schools.

\section{References}

[1] Allen R, Jerrim J\& Sims S. (2020) How Did the Early Stages of the COVID-19 Pandemic Affect Teacher Wellbeing? Centre for Education Policy and Equalising Opportunities (CEPEO) Working Paper; 2020

[2] Cuervo TC, Orviz, N. M, Arce SG \& Fernández IS (2018) Technostress in communication and technology society: scoping literature review from the Web of science. Archivos Prevencion Riesgos Laborales 2018, $18-25$

[3] Duraku, Zamira \& Hoxha (2020) The impact of COVID-19 on education and on the well-being of teachers, parents, and students: Challenges related to remote (online) learning and opportunities for advancing the quality of educationinhttps: //www.researchgate.

net/publication/341297812_The_impact_of_COVI19_ on_education_and_on_the_wellbeing_of_teachers_par ents_and_students_Challenges_related_to_remote_onli ne_learning_and_opportunities_for_advancing_the_qu ality_of_education/citation/download

[4] Hasson, R., Sallis, J. S., Coleman, N. (2021) COVID19: Implications for Physical Activity, Health Disparities, and Health Equity. American Journal of LifestyleMedicinehttps: //journals. sagepub. com/doi/full/10.1177/15598276211029222

[5] Huang Y, Zhao N. (2020) Generalized anxiety disorder, depressive symptoms and sleep quality during COVID-19 outbreak in China: a web-based cross-sectional survey. Psychiatry Res.2020; 288: 112954. doi: 10.1016/j. psychres.2020.112954

[6] Hyseni, D., Zamira \& Hoxha, L. (2020). The impact of COVID-19 on education and on the well-being of teachers, parents, and students: Challenges related to remote (online) learning and opportunities for advancing the quality of education.

[7] Klapproth F, Federkeil L, Heinschke FJungmann T. (2020) Teachers experiences of stress and their coping strategies during COVID-19 induced distance teaching. J Pedagog Res.2020; 4 (4): 444-452. doi: 10.33902/JPR.2020062805

[8] Lizana PA, Vega-Fernadez G, Gomez-Bruton A, Leyton B, Lera L. Impact of the COVID-19 pandemic on teacher quality of life: a longitudinal study from before and during the health crisis. Int J Environ Res Public Health.2021; 18: 3764. doi: 10.3390/ ijerph18073764

[9] Pai, N. and Vella, S. L. (2021) COVID-19 and loneliness: A rapid systematic review. Australian \& New Zealand Journal of Psychiatry 1-13.

[10] Ryan S. V., Nathaniel P., Pendergast L. L., Saeki E., Segool N., Schwing S. (2017). Leaving the teaching profession: The role of teacher stress and educational accountability policies on turnover intent. Teaching Teacher Educ.66 1-11.10.1016/j. tate.2017.03.016 [CrossRef] [Google Scholar

[11] Smith B. J., Lim M. H. (2020). How the COVID-19 pandemic is focusing attention on loneliness and social isolation. Public Health Res. Pract.30: 3022008.10.17061/phrp3022008 [PubMed] 
[12] Sheikh A., Sheikh A., Sheikh Z., Dhami S. (2020). Reopening schools after the COVID-19 lockdown. J. Glob. Health 10: 010376.10.7189/jogh.10.010376 [PMC free article] [PubMed] [CrossRef] [Google Scholar]

[13] United Nations Educational, Scientific and Cultural Organization (UNESCO) (2020a). Adverse effects of school closures, 2020. paris: UNESCO. [Google Scholar]

[14] Van Lancker W., Parolin Z. (2020). COVID-19, school closures, and child poverty: a social crisis in the making. Lancet. Public Health 5 e243e244.10.1016/S2468-2667 (20) 30084-0 [PMC free article] [PubMed] [CrossRef] [Google Scholar]

[15] Viner R. M., Russell S. J., Croker H., Packer J., Ward J., Stansfield C., et al. (2020). School closure and management practices during coronavirus outbreaks including COVID-19: a rapid systematic review. Lancet Child Adolesc. Health 4 397404.10.1016/S2352-4642 (20) 30095-X

[16] Von der Embse N., Ryan S. V., Gibbs T., Mankin A. (2019). Teacher stress interventions: a systematic review. Psychol. Schools 56 1328-1343. [Google Scholar]

[17] Wang, C., and Zhao, H. (2020). The Impact of COVID-19 on Anxiety in Chinese University Students. Front. Psychol.11: 1168 . doi: 10.3389/fpsyg.2020.01168

[18] Self Composed Questionnaire available at https: //forms. gle/h5Ht7qbBnotqsT9B7 